\title{
Organo Silica Membranes for Wetland Saline Water Desalination: Effect of membranes calcination temperatures
}

\author{
Riani Ayu Lestari ${ }^{1,2}$, Muthia Elma ${ }^{1,2 *}$, Aulia Rahma ${ }^{1,2}$, Dewi Suparsih ${ }^{1,2}$, Syarifah Anadhliyah ${ }^{1,2}$, Norlian Ledyana Sari ${ }^{1,2}$, \\ Dhimas Ari Pratomo ${ }^{1,2}$, Anna Sumardi ${ }^{1,2}$, Aptar Lestari ${ }^{1,2}$, Zaini Lambri Assyaifi ${ }^{1,2}$, and Gesit Satriaji ${ }^{1,2}$ \\ ${ }^{1}$ Department of Chemical Engineering, University of Lambung Mangkurat, Banjarbaru. South Kalimantan. Indonesia \\ ${ }^{2}$ Materials and Membranes Research Group ( $\mathrm{M}^{2} \mathrm{ReG}$ ), University of Lambung Mangkurat, Banjarbaru, South Kalimantan, Indonesia
}

\begin{abstract}
Wetland saline water has great potential to overcome water scarcity due to high salinity of intruded seawater. This work determines performance of silica membranes using organo catalyst applied for wetland saline water desalination via pervaporation and investigates the effect of calcination temperatures. These membranes were prepared from precursor tetraethyl orthosilicate (TEOS) for $3 \mathrm{~h}$ through sol-gel process refluxed at $0^{\circ} \mathrm{C}$ (membrane $\mathrm{A}$ ) and $50^{\circ} \mathrm{C}$ (membrane $\mathrm{B}$ ). The sols were dipcoated onto alumina $\left(\mathrm{Al}_{2} \mathrm{O}_{3}\right)$ support for 4 layers followed by calcination for $1 \mathrm{~h}$. Performance of membranes were evaluated by feeding wetland saline water through desalination at room temperature. Results show the water flux for membrane A were $0.27 \& 0.15 \mathrm{~kg} \cdot \mathrm{m}^{-2} \cdot \mathrm{h}^{-1}$ and salt rejection were $97.5 \& 99 \%$ as a function of calcination temperature $\left(200 \& 250^{\circ} \mathrm{C}\right)$, respectively. Furthermore, water flux of membranes B were $0.90 \& 0.93 \mathrm{~kg} . \mathrm{m}^{-}$ ${ }^{2} \cdot \mathrm{h}^{-1}$ and excellent salt rejection $(>99.9 \%$ ) for both calcination temperatures. The highest water flux and salt rejection were found for membranes $\mathrm{B}$. For both using citric acid under refluxed and calcination process, it gives more vibration of $\mathrm{Si}-\mathrm{C}$ formation and membrane pores. This membrane is the very first and mesoporous organo silica membranes which is successfully fabricated from organo catalyst.
\end{abstract}

\section{Introduction}

Increasing of water scarcity issues when the earth consist of $97.5 \%$ water but only $2.5 \%$ of proper consumption gives the big impact for fulfillment of life's needs. Indonesia is in high stress level (40-80\%) representing the ration of withdrawal to supply of water [1]. The greatest issue of world's water scarcity has been encountered in Indonesia which is as the world's largest archipelago. South Kalimantan as the largest island in Indonesia characterized by wetland whereas the height of soil at 0.16 under sea level is important in hydrology and big potential as water reservoir. The rivers connect to the sea. During rainy season the seawater intrudes into rivers and salty water formed. However, wetland saline water as a big source of clean water requires for contaminant removal process.

Desalination using membrane is one of technology to increase quality of wetland saline water. Desalination technology enlarged widely through varying method by using membranes, such as reverse osmosis, membrane distillation and pervaporation [2]. Pervaporation comes as other method accompanying with high performance, lower cost and high level operating [3]. Pervaporation operates on changing phase to separate between water molecule and hydrated ion under vacuum condition employing selective semipermeable membrane. The mechanism shows in Figure 1 (b).
Commonly, inorganic membrane from silica based is affordable to be used for pervaporation process due to its simple fabrication technique, more stable for high temperature, robustness, offering high molecular sieving and relatively low cost $[4,5]$. Besides, having 5 $\AA$ silica amorf as structural molecular sieving properties is suitable particularly when applied in desalination. Thus, membrane has high potential to separate small molecule water and hydrated salt ion through pore small pathway [6, 7]. TEOS (tetra ethyl ortho silicate) as hydrophobic inorganic material from metal alkoxide (precursor) is skillfully utilized for membrane synthetic[8].

Desalination using silica membrane has been investigated to remove the salt content in the raw water. However, most of separation technology using membrane has big problem in hydrostability. Consequently, membrane becomes dense and swell earlier thus decreasing on water flux and salt rejection[9]. Membrane damage because of silanol (Si$\mathrm{OH})$ content which is high reacted with water. Solving for decreasing performance of membrane due to hydrophilic, some strategies was run for membrane modification. The strategies consist of surface functionalization using metal doping [10], carbonized templeting [11] and induced organo material into silica matrices [12].

\footnotetext{
*Corresponding author: m.elma@ulm.ac.id
} 
Previous work has been reported that organosilica membrane was prepared by templating carbon material such as P123 and pectin which is approve to enhance silica membrane performance [13, 14]. However, that method was spent much time to templating carbon agent into silica thin film. In this work, fabrication of organosilica membrane takes short time relatively than templating method by using organo catalyst. Organo catalyst from citric acid acts as carbon sources which able to increasing hydrostability of silica matrices [15].

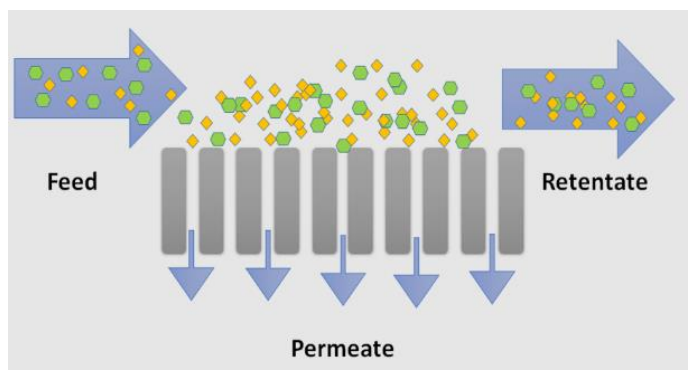

In addition, rapid thermal processing (RTP) technique is more attracted to applies for membrane calcination also in this work. RTP technique is offering shorten time to production of membrane and lessen the cost [16]. This work aims to evaluate the performance of organosilica membrane using precursor TEOS and citric acid catalyst for wetland saline water desalination via pervaporation and investigate effect of calcination temperature.

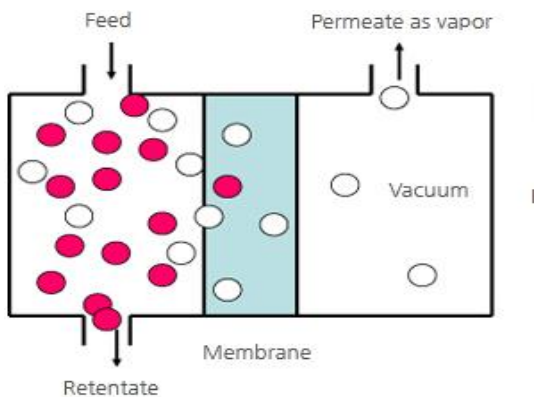

Figure 1. Mass transfer mechanisms of (a) separation technology using membrane; (b) desalination via pervaporation

\section{Experimental}

\subsection{Materials and Synthesis of Membrane}

In this section, some of material need initial treatment before mixed. Firstly, pretreatment was prepared to precursor (TEOS, 99.0\%, Sigma-Aldrich), $0.0007 \mathrm{~N}$ citric acid, ethanol solution (EtOH 70\%), water and support membrane $\left(-\mathrm{Al}_{2} \mathrm{O}_{3}\right)$. Organosilica membrane was synthesized through sol-gel process including hydrolysis and condensation reaction for $3 \mathrm{~h}$ by employing citric acid catalyst. Silica sol was refluxed at $0^{\circ} \mathrm{C}$ and $50^{\circ} \mathrm{C}$. Ratio molar TEOS:EtOH: $\mathrm{C}_{6} \mathrm{H}_{5} \mathrm{O}_{7}: \mathrm{H}_{2} \mathrm{O}$ is 1: 38:0.0007:5.

Then, for dip-coating step silica sol was poured into centrifuge cube putting on Erlenmeyer. Support membrane was stapled on dip-coater (run in $5 \mathrm{~cm} / \mathrm{s}$ ) for 2 minutes in soaked. Coated membrane on support membrane was calcined at $200^{\circ} \mathrm{C}$ and $250^{\circ} \mathrm{C}$ for 1 hours each. Coated membrane was cooled at room temperature and continue to repeating dip-coating for 4 times to form 4 layers of membranes.

\subsection{Material and Characterization of membrane}

This process employed citric acid as organic catalyst. Firstly, EtOH was added into reagent bottle followed by cooling process at $0^{\circ} \mathrm{C}$ and stirring at $250 \mathrm{rpm}$ for 5 minutes. Then TEOS was dropped wise and resting. After resting for 5 minutes TEOS and $\mathrm{EtOH}$ mixture was dropped wise by $\mathrm{C}_{6} \mathrm{H}_{8} \mathrm{O}_{7}$ to produce sol through onestep sol gel process.
Silica sol was dried in oven at temperature controlled $60^{\circ} \mathrm{C}$ for 24 hours to create dried gel. Dried gel (xerogels) was subsequently grounded into fully homogeny powder and calcined in temperature controlled at varying temperature $200^{\circ} \mathrm{C}$ and $250^{\circ} \mathrm{C}$ for $4 \mathrm{~h}$. Xerogels were characterized using FTIR at wavelength range 1400-600 1/cm.

\subsection{Characterization Using FTIR}

FTIR as one method of indirect analysis can assist to provide information of functional group within the silica network[17, 18]. According to presence hypothesis of silanol, siloxane and $\mathrm{Si}-\mathrm{C}$ bonds in matrix, Infrared spectra was carried out along with $1400-600 \mathrm{~cm}^{-1}$ wavelength. Socrates (2011) listed some peak relates to organic compound and silicone alkoxide. Wavenumber for Si-C, Si-O-Si and Si-OH are $1260 \mathrm{~cm}^{-1}, 1000-1100$ $\mathrm{cm}^{-1}$, and $940 \mathrm{~cm}^{-1}$, respectively [19].

\section{Results and Discussion}

\subsection{Organosilica Membrane and Hydrostability}

Organosilica membrane was prepared through sol gel process including hydrolysis and condensation reaction. Sol gel is a process to synthesize inorganic compound through chemical reaction in solution under low temperature converting sol to gel. Inorganic acid was rarely used for sol gel reaction, such as $\mathrm{HCl}, \mathrm{HNO}_{3}$ and $\mathrm{H}_{2} \mathrm{SO}_{4}$. On the other hand, organic acid was also used as catalyst for gel forming and its physical properties [20].

TEOS is in solution phase and as major material to synthesize inorganic membrane. Precursor TEOS will 
be reacted during hydrolysis and condensation process to form silica network. During hydrolysis reaction, alkoxide group (OR, whereas $\mathrm{R}$ is alkyl group, $\mathrm{C}_{\mathrm{x}} \mathrm{H}_{2 \mathrm{x}+1}$ ) was replaced by hydroxyl group $(\mathrm{OH})$. Then, silanol group $(\mathrm{Si}-\mathrm{OH})$ reacted and produced siloxane $(\mathrm{Si}-\mathrm{O}-\mathrm{Si})$, alcohol (R-OH) and water. Equation of hydrolysis, alcohol condensation and water condensation were described in equation (1), (2), and (3), respectively.

$$
\equiv \mathrm{Si}-\mathrm{OR}+\mathrm{H}_{2} \mathrm{O} \quad \stackrel{\text { hydrolisis }}{\stackrel{\text { esterification }}{\rightleftarrows}} \equiv \mathrm{Si}-\mathrm{OH} \text {. }
$$

$$
\begin{aligned}
& \equiv \mathrm{Si}-\mathrm{OR}+\mathrm{HO}-\mathrm{Si} \equiv \underset{\text { Alcoholysis }}{\stackrel{\substack{\text { Alcohol } \\
\text { Condensation }}}{\rightleftarrows}} \equiv \mathrm{Si}-\mathrm{O}-\mathrm{Si} \equiv+\mathrm{R}-\mathrm{OH} \\
& \equiv \mathrm{Si}-\mathrm{OH}+\mathrm{HO}-\mathrm{Si} \equiv \underset{\begin{array}{c}
\text { Siloxane } \\
\text { Hydrolysis }
\end{array}}{\stackrel{\substack{\text { Water } \\
\text { Oondensation }}}{\rightleftarrows}} \equiv \mathrm{Si}-\mathrm{O}-\mathrm{Si} \equiv+\mathrm{H}_{2} \mathrm{O} \ldots
\end{aligned}
$$

Due to affinity of amorphous silica, structural degradation happen when exposing into water. Briefly, silica surface has big tendency on physisorption of water molecule on silanol groups ( $\mathrm{Si}-\mathrm{OH})$ during hydrolysis step as shown in equation (1). Hence, acid and base catalyst help for up taking of water. Big problem of using hydrophobic membrane is hydrostability. There are many researchers have been delivered for surface silica modification. In particular, there are three method, such as carbon template silica, hybrid organic-inorganic silica and metal oxide silica[21]. During on latest decade, technique to increase hydrostability was proposed on existence of organic compound that tailored into silica network [22]. Existence of carbon side effected in hydrophobic properties. Some of modification to improve existence carbon compound described into some methods. Modification in templeting carbon using Pluronics triblock copolymers [11] and surfactant. Besides, Elma et al (2015) synthesize silica membrane from precursor TEOS and Pluronics P123 as templeting agent through sol gel process.

Micro structure from silica membrane was determined by reactivity, precursor size and exacting composition among precursor concentration, alcohol and catalyst. For silicon alkoxide, acid condition was particularly produced structural fractal of sols and encouraged to mesopored silica [3].

In this work, membrane was prepared through sol gel process employing citric acid catalyst for two types of reflux condition, $0^{\circ} \mathrm{C}$ and $50^{\circ} \mathrm{C}$ followed by calcination at $200^{\circ} \mathrm{C}$ and $250^{\circ} \mathrm{C}$. Organic catalyst has two responsibilities that are for supporting high kinetic reaction in sol gel process and as carbon source to assist silica-carbon bond into silica network.

\subsection{Characterization of Xerogels}

Hydro-stability and pore size are the fundamental qualifications in determining the characterizations of a membrane applied to water-contaminant separation techniques. In order to increase hydro-stability and robustness of membrane against both physical and chemical resistances, carbon silica configuration is an important group tailored into silica network. In Figure 2 wavelength at $1068 \mathrm{~cm}^{-1}, 926 \mathrm{~cm}^{-1}$, and $788 \mathrm{~cm}^{-1}$ are wavenumber of siloxane, silanol and silica-carbon, respectively.

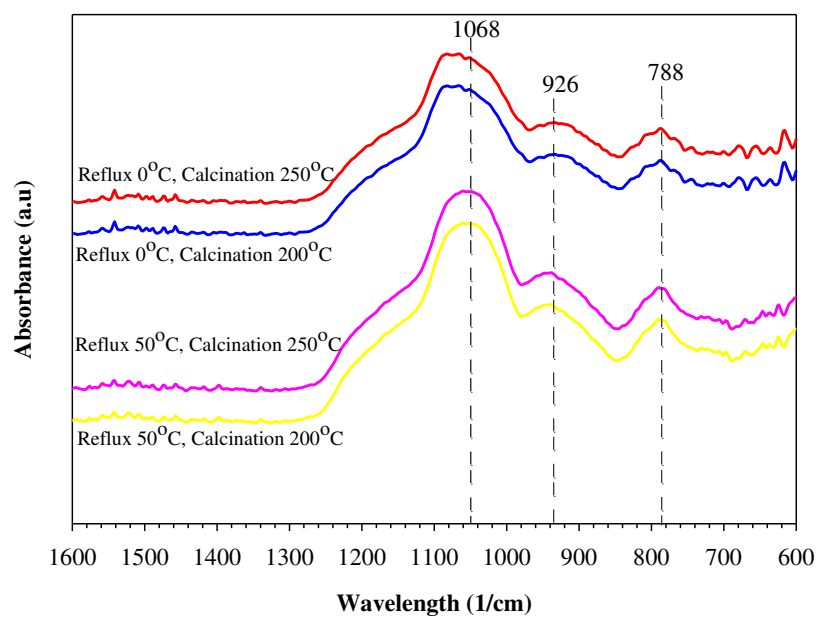

Figure 2. FTIR Spectra of xerogel as thin film for organo silica membrane

As shown in Figure 2, there are two differences trend line between two types of membrane, type A for $0^{\circ} \mathrm{C}$ refluxed and type $\mathrm{B}$ for $50^{\circ} \mathrm{C}$ refluxed. Sol gel process systematically includes hydrolysis, condensation, aging and drying. Reflux temperature effects polymerization process particularly in aging step [23]. Particles grow fast under reflux condition thus physically effects in ratio of bond to form silica network.

After sol gel process finished, then continued to calcination step as endothermic decomposition process to discharge gas contaminant, for example carbonate or hydroxide ion. Calcination process consists of (a) discharging of free water $\left(\mathrm{H}_{2} \mathrm{O}\right)$ and bound water $(\mathrm{OH})$ at $100-300^{\circ} \mathrm{C}$; (b) discharging of gas at $600^{\circ} \mathrm{C}$ followed by significant mass decreasing and at $800^{\circ} \mathrm{C}$ assist to network damaging [24]. For both variation low temperature $\left(200\right.$ and $\left.250^{\circ} \mathrm{C}\right)$ and types of catalyst do not show significant differences of trend line. Interestingly, for silica carbon is able to stick out into silica network. Existence of silica carbon into silica network support to high robust of membranes.

\subsection{Permeation Performance}

Duke et al (2009) reported that high salt rejection was resulted during desalination via pervaporation using only oxide silica membranes. Elma (2013) prepared silica membrane through two step sol gel reaction using TEOS by employing nitric acid-ammonia (as catalyst). In order to investigate membranes quality, it was applied to desalinate $0.3-15 \mathrm{wt} \%$ sodium chloride feed water as artificial seawater. Results showed that the water flux and salt rejection with decreasing salt concentration on $9.5 \mathrm{~kg} \cdot \mathrm{m}^{-2} \cdot \mathrm{h}^{-1}(99.6 \%)$ and $1.55 \mathrm{~kg} \cdot \mathrm{m}^{-2} \cdot \mathrm{h}^{-1}$ from 0.3 and 15 -wt $\%$ saline feed solution, respectively [25]. 
The pervaporation process gives many variables for execute desalination performance. It takes two aspect: (1) flux of water and (2) salt rejection. Also, permeate water is captured in a condenser and flux $\left(\mathrm{kg} . \mathrm{m}^{-2} \mathrm{~h}^{-1}\right), \mathrm{F}$, of water during given time period is calculated as $F=$ $M /(S . t)$, where $M$ is mass of permeate $(\mathrm{kg}), S$ is the surface area of membrane $\left(\mathrm{m}^{2}\right)$ and $t$ is the performance test time (h). Also, percentage of salt rejection was described in mathematical formulation as $R=\{(C f-C p)\}$ $C f$ ) $100 \%$, where $C_{f}$ and $C_{p}$ are the concentrations of salt in the feed and permeate solutions, respectively, using conduct meter measurement.

Table 1. Desalination performance comparison for silica membranes

\begin{tabular}{|c|c|c|c|c|c|c|}
\hline $\begin{array}{c}\text { Types of } \\
\text { silica } \\
\text { membrane }\end{array}$ & $\begin{array}{c}\text { Desalination } \\
\text { Method }\end{array}$ & $\begin{array}{c}\text { Feed } \\
\text { Temp. }\left({ }^{\mathbf{o}} \mathbf{C}\right)\end{array}$ & $\begin{array}{c}\text { Feed } \\
\text { concentration }(\%)\end{array}$ & $\begin{array}{c}\text { Water Flux } \\
\left(\mathbf{k g} \cdot \mathbf{m}^{-\mathbf{2}} \cdot \mathbf{h}^{\mathbf{- 1}}\right)\end{array}$ & $\begin{array}{c}\text { Salt } \\
\text { Rejection } \\
(\boldsymbol{\%})\end{array}$ & References \\
\hline Organo silica & Pervaporation & $\begin{array}{c}\text { Room } \\
\text { temp. }\end{array}$ & $\begin{array}{c}\text { Wetland saline } \\
\text { water }\end{array}$ & 0.93 & $>99$ & This work \\
\hline Organo silica & $\begin{array}{c}\text { Reverse } \\
\text { osmosis }\end{array}$ & 20 & $0.3-3.5$ & $4.7-2.5$ & $93.7-83$ & {$[26]$} \\
\hline Organo silica & Non-osmotic & 30 & 0.2 & 3.0 & 99 & {$[27]$} \\
\hline $\begin{array}{c}\text { Pure silica } \\
\text { TEOS pH 6) }\end{array}$ & Pervaporation & 22 & $3.5-15$ & $6.8-1.6$ & $98-89$ & {$[25]$} \\
\hline Organo silica & Pervaporation & 60 & $\begin{array}{c}\text { Brackish (1\%-w) } \\
\text { Brine }(15 \%-w)\end{array}$ & $\begin{array}{c}26.5 \\
9.2\end{array}$ & 99.5 & {$[28]$} \\
\hline
\end{tabular}

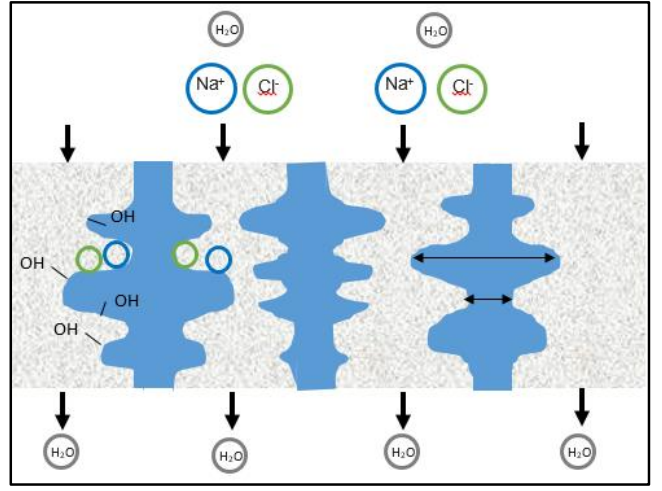

(a)

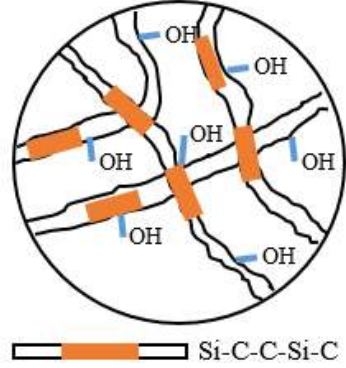

(b)

Figure. 3 (a) schematic illustration for salt and water transport during pervaporation, (b) representation of silica matix

Performance in separation using membrane aims to measure membrane capability for separating salt ion and water molecule. High water flux and salt rejection effect in high membrane performance. On the other hand, performance was effected in membrane structure (mesopore).

In Figure 4 shows the water flux for membrane A (refluxed at $0^{\circ} \mathrm{C}$ ) were $0.27 \& 0.15 \mathrm{~kg} \cdot \mathrm{m}^{-2} \cdot \mathrm{h}^{-1}$ and salt rejection were $97.5 \& 99 \%$ as a function of calcination temperature $\left(200 \& 250^{\circ} \mathrm{C}\right)$, respectively. Additionally, water flux of membranes B were $0.90 \& 0.93 \mathrm{~kg} \cdot \mathrm{m}^{-2} \cdot \mathrm{h}^{-1}$ and excellent salt rejection $(>99.9 \%)$ for both calcination temperatures. The highest water flux and salt rejection were found for membranes $\mathrm{B}$.

Calcination effects membrane performance basically due to existence of silica-carbon in silica network. Table 1 shows comparison among similar research about desalination. Organosilica employing organic compound for sol gel process has a big contribution in desalination.

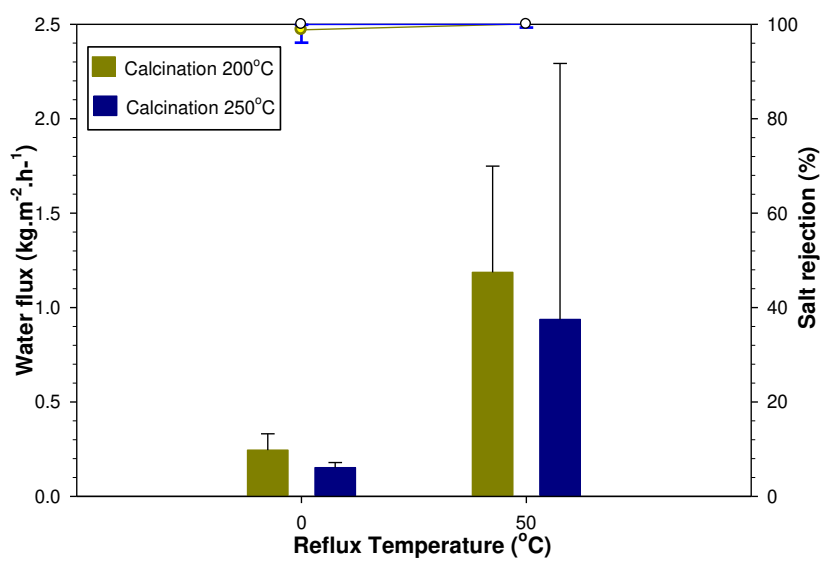

Figure 4. The water flux (vertical bar) and salt rejection values of organo silica membranes as function of reflux temperature for desalination feeding at room temperature

\section{Conclusion}


By employing citric acid catalyst through sol gel reaction refluxed at $50^{\circ} \mathrm{C}$, organo silica membranes were successfully synthesized. Compared to many other method for existing carbon compound, employing acid catalyst could be able to eliminate one step process in templeting carbon for cost decreasing relevance.

Organo silica was applied into desalination via pervaporation feeding by wetland saline water at room temperature. The water flux and salt rejection values show an excellent value for membrane refluxed at $50^{\circ} \mathrm{C}$. Interestingly, the IR spectra shows carbon chains in the silica matrices. It comes from organo catalyst employed during sol gel process.

The authors gratefully thank the facilities of Process Technology Laboratory, Engineering Faculty, University of Lambung Mangkurat. Riani Ayu Lestari thanks to KURITAAIT Research Grant 2018. Muthia Elma thanks to Alumni Grants Scheme Batch 2 (2018-2019); Applied Research Universities Grant (2019-2020); Grant of Thesis Magister 2019 and Grant of Post-Doctoral (2017-2018) Directorate of Research and Community Service, the Ministry of Research, Technology and Higher Education Republic of Indonesia.

\section{References}

1. Gassert, e.a. Water Stress by Country. 2013 [cited 2018.

2. Duke.M.C, O.B.-A.J., Milne.N,Zhu,B,Lin.J\&Diniz da Costa, Seawater desalination perfromance. Sep.Purif.Technol, 2009. 68: p. 629.

3. M.Elma, C.Y., D.K.Wang, S.Smart, J.C. Diniz da Costa, Microporous Silica Based Membrane for Desalination. Journal of Water, 2012.

4. Duke, M.C., S. Mee, and J.C.D. da Costa, Performance of porous inorganic membranes in non-osmotic desalination. Water Research, 2007. 41(17): p. 3998-4004.

5. Chen, L., et al., Investigation of the long-term desalination performance of membrane capacitive deionization at the presence of organic foulants. Chemosphere, 2018. 193: p. 989-997.

6. M.C. Duke, S.M., J.C. Diniz da Costa, Performance of porous inorganic membranes in ion-osmotic desalination. Water Res, 2007. 41: p. 3998-4004.

7. S. Wijaya, M.C.D., J.C. Diniz da Costa, Cobalt oxide silica membranes for desalination. J. Colloid Interface Sci, 2012. 368: p. 70-76.

8. H. Yan, W.Y., Y.Hongxing, TEOS/silane coupling agent composed double layers structure: A novel super-hydrophilic coating with controllable water contact angle value. Applied Energy, 2015.

9. L.Liu, D.W., Influence of sol gel conditioning on the cobalt phase. Membranes Sci, 2015. 475: p. 425-432.

10. Lin, C.X.C., et al., Cobalt oxide silica membranes for desalination. Journal of colloid and interface science, 2012. 368(1): p. 70-76.
11. Ladewig, B.P., et al., Preparation, Characterization and Performance of Templated Silica Membranes in Non-Osmotic Desalination. Materials, 2011. 4(5): p. 845.

12. Tsuru, T., et al., Permeation properties of hydrogen and water vapor through porous silica membranes at high temperatures. AIChE Journal, 2011. 57(3): p. 618-629.

13. Elma, M., et al. Fabrication of Interlayer-free P123 Caronised Template Silica Membranes for Water Desalination: Conventional Versus Rapid Thermal Processing (CTP vs RTP) Techniques. in IOP Conference Series: Materials Science and Engineering. 2019. IOP Publishing.

14. Rahma, A., et al., Removal of natural organic matter for wetland saline water desalination by coagulation-pervaporation. Jurnal Kimia Sains dan Aplikasi, 2019. 22(3): p. 85-92.

15. Elma, M., et al., Fabrication of interlayer-free silica-based membranes - effect of low calcination temperature using an organo-catalyst. Membrane Technology, 2019. 2019(2): p. 6-10.

16. Pratiwi, A.E., et al., Deconvolution of pectin carbonised template silica thin-film: synthesis and characterisation. Membrane Technology, 2019. 2019(9): p. 5-8.

17. M. Elma, D.K.W., C. Yacou, J.C.Diniz da Costa, Interlayer-free P123 carbonised templete silica membranes for desalination with educed salt concentration polarisation. J. Membr. Sci, 2015a. 475: p. 376-383.

18. Y. T. Chua, C.X.C.L., F. Kleitz, and S. Smart, Sythesis of mesoporous carbon-silica nanocomposite water-treatment membranes using a triconstituent co-assembly method. J. Mater. Chem. A., 2015. 00: p. 1-3.

19. Socrates, G., Infrared and Raman Characteristics Group Frequencies: Tables and Charts. 3rd ed. 2001, West Sussex: John Wiley \& Sons Ltd.

20. Singh, L.P., Agarwal, S.K., Bhattachayya, S.K.,Sharma,U.,\& Ahalawat,S, Preparation of Nanoparticles and its beneficial Role In Cementitious Materials. Nanomaterials and Ananotechnology, 2011. 1: p. 44-51.

21. Ayral, A., et al., Microporous Silica Membrane: Basic Principles and Recent Advances, in Membrane Science and Technology. 2008, Elsevier. p. 33-79.

22. Giessler.S, J., L.Diniz da Costa. J.C, Lu.G.Q, Pefromance of hydrophobic and. Sep. Purif. Technol, 2003. 32: p. 255-264.

23. Brinker, C.J., Scherer, G.W, Sol-Gel Science : The Physics and Chemisty of Sol-Gel Processing. Academic Press: San Diego, CA, 1990.

24. James, S.R., Introduction to the principles of ceramic processing. John Willey and Sons Inc, New York, 1988.

25. M.Elma, D.K.W., J.C. Diniz da Costa C. Yacou, Performance and Long Term Stability of Mesoporous Silica Membranes for Desalination. Journal of Membranes. 2013. 
26. Chua.Y.T, L.C.X.C., Kleitz.F,Zhao.X.S,Smart.S, Nanpoporous organosilica membrane. Chem. Commun, 2013. 49: p. 4534-4536.

27. Duke.M.C, M.S., Diniz daCosta, J.C., Performance of porous inorganic membrane. Water Res, 2007. 41: p. 3998-4004.

28. Yang, H., et al., Interlayer-Free Hybrid CarbonSilica Membranes for Processing Brackish to Brine Salt Solutions by Pervaporation. Journal of Membrane Science, 2017. 